\title{
Homelessness and Incarceration: An Examination of Barriers to Misdemeanor Resolution for the Homeless
}

\author{
Joseph R. Herzog ${ }^{1}$, Chang-Bae Lee ${ }^{2, *}$, Frank A. Sansone ${ }^{1}$ and Mark Olson ${ }^{1}$ \\ ${ }^{1}$ Department of Social Work, University of West Florida, 11000 University Parkway, Pensacola, FL 32514, \\ USA \\ ${ }^{2}$ Department of Police Science, University of Ulsan, 93 Daehangro, Ulsan, South Korea
}

\begin{abstract}
The relationship between homelessness and crime has been investigated in few studies despite the implications of prior offenses and incarceration on job seekers. This study examined the relationship among homelessness, misdemeanors, incarceration, and misdemeanor resolution. Factors hindering misdemeanor resolution were explored by surveying participants at two Veterans Administration (VA) Stand Downs $(n=186)$. The sample includes the primary service population of homeless veterans and other homeless persons. Respondents reported on factors perceived as limiting them from resolving misdemeanors, along with socio-demographic, homeless status, misdemeanor, and incarceration data. Factor Analysis yielded three factors as barriers that have implications for social work practice.
\end{abstract}

Keywords: Homelessness, veterans, misdemeanor, incarceration, misdemeanor resolution.

\section{INTRODUCTION}

Homelessness continues to be a significant area for international, national, state, and local governmental policy. One of the hurdles some of the homeless population face is outstanding low-level misdemeanor charges on their criminal record. There has been little study of the reasons why some homeless persons fail to resolve misdemeanor charges which impede their transition into society.

In general, crimes are classified as either misdemeanors or felonies (www.misdemeanorguide.com/Florida-misdemeanor.php). Misdemeanor crimes are classified into two categories as either first or second degree. In Florida first degree misdemeanor charges have a punishment of up to one year of imprisonment in a county jail and a thousand dollar fine. In contrast, a second degree misdemeanor is punishable with up to sixty days in jail and a five hundred dollar fine. Florida differs from other states in that it has a third classification - noncriminal violation with penalties of forfeiture, fines, or civil remedy. Some examples of misdemeanor charges are: disorderly conduct, public drunkenness, panhandling, resisting arrest, domestic assault, petty theft, vandalism, and others (www.misdemeanorguide.com/Floridamisdemeanor.php).

Florida courts must impose one of three sentencing options for someone found guilty of a misdemeanor:

*Address corresponding to this author at the Department of Police Science, University of Ulsan, 93 Daehangro, Ulsan, South Korea; Tel: 82.52.259.2717; Fax: 82.52.259.1719; E-mail: changbaelee@ulsan.ac.kr
1) imprisonment in county jail for no less than six months but no more than one year;

2) commitment to a residential treatment program of the same duration as option one; or 3) detention in a designated residence for the same duration as the first two options (www.misdemeanorguide.com/Floridamisdemeanor.php).

Another option for those charged but not yet "found guilty" is "misdemeanor expungement" with conditions provided for in Florida Statute 943.0585. "Expungement" allows for the sealing of court cases and for the person to be able to say a crime was never convicted. (www.misdemeanorguide.com/Floridamisdemeanor.php)

Misdemeanor charges can have a deleterious effect on an individual's employability, homeless status, housing opportunities, supportive social services, and how future offenses are viewed. This paper explores factors hindering homeless individuals from resolving their misdemeanor charges and the implications for social and court services in the future.

\section{LITERATURE REVIEW}

The causes of homelessness are multifaceted and influenced by factors within the social environment and the individual. However, the conceptualization and ultimately the approaches to resolving the problem of homelessness are significantly influenced by cultural values and definitions of the problem. Minnery and Greenhalgh (2007) have argued that in order to address the problem of homelessness, it is necessary 
to begin with a clear definition of the term. However, conceptualizations of homelessness vary across cultures, from broader definitions that include inadequate or insecure living conditions (as more commonly defined in European cultures) to narrower definitions of not having shelter and living on the street (more common in American culture).

The Stewart B. McKinney Act, 42 U.S.C. 11301, et seq. (1994) defines a person as homeless who "lacks a fixed, regular, and adequate night-time residence; and... has a primary night-time residence that is: $(A)$ a supervised publicly or privately operated shelter designed to provide temporary living accommodations... (B) An institution that provides a temporary residence for individuals intended to be institutionalized, or (C) a public or private place not designed for, or ordinarily used as, a regular sleeping accommodation for human beings." In addition, note the term "homeless individual" does not include any individual imprisoned or otherwise detained pursuant to an Act of Congress or a state law" (42 U.S.C. 11302(c) as cited in National Coalition for the Homeless, 2012, p. 1). As noted in the Annual Report of Florida's Council on Homelessness (2010, p.15), the federal definition of a homeless person is narrower than the state law in Florida. Effective July 1, 2009, the Florida Legislature amended the definition to also include:

A person sharing the housing of family or friends due to the loss of their own housing, economic hardship or similar reason;

A person living in a motel, travel trailer park or campground due to their lack of an adequate housing alternative. (Florida Council on Homelessness, 2010, p.15).

One conceptualization frequently cited in the literature defines homelessness along a continuum allowing for a broader understanding of the issue. The European Federation of National Organizations Working with the Homeless (FEANTSA) has attempted to operationalize homelessness along the following domains: insecure or inadequate housing (e.g., residing in temporary or overcrowded structures); "houselessness" (e.g., residing in temporary shelter); and "rooflessness" (i.e., living on the street or public spaces) (FEANTSA, 2010, p. 4). That definition allows for a more comprehensive understanding of the problem, and includes groups (e.g., families, immigrants) not included in previous conceptualizations of the term.
Prior research identified an interaction between structural and individual risk factors underlying homelessness (Minnery \& Greenhalgh, 2007). Many incarcerated individuals have been homeless at some point in their lifetime. Greenberg and Rosenheck (2008) found $15.3 \%$ of the U.S. Jail population reported being homeless in the year prior to incarceration. Cohen (1999) identified a history of imprisonment as a significant risk factor for incidents of homelessness in middle and later life. The risk factor of prior imprisonment for becoming homeless may be related to the disenfranchisement that often follows a criminal conviction (Shinn, 2007). One study of homelessness among middle-aged and older adults (Crane et al., 2005) identified "criminality" as a "contributing factor" to homelessness; however, "antecedents" or "triggers" to homelessness were more likely to be structural factors such as a lack of affordable housing. Committing property crimes and having prior offenses were positively related to homelessness while having a GED and being incarcerated for over one month were negatively related. Homeless veterans appear to be at particular risk for legal involvement with the criminal justice system (Seidner, Burling, Fisher, \& Blair, 1990), with $71 \%$ reporting prior arrest(s) during their lifetime. Of those reporting prior arrests, the highest percentage $(41 \%)$ was for substance abuse related incidents.

Related research (Tolomiczenko \& Goering, 2001) identified the following factors as contributing to legal involvement among the homeless: substance abuse, childhood poverty, sexual abuse, and child conduct disorders. Another study (Crane et al., 2005) also noted homeless individuals often suffer higher rates of drug and alcohol abuse as well as psychiatric disorders. Indeed mental health is a risk factor as severely mentally ill individuals are at high risk for substance abuse and homelessness (White, Chafetz, Collins-Bride, \& Nickens, 2006). Related research reported accessibility to residential psychiatric treatment as being associated with lower rates of homelessness in urban areas in the United States (Elliott \& Krivo, 1999).

In regard to involvement with the legal system, gender has played a role with women displaying differing patterns of legal involvement, including women being less likely to be held overnight by authorities. In many parts of the United States, a criminal conviction may result in losing access to various forms of welfare assistance, including subsidized housing, often necessary for re-entry into society (Travis, 2002). One researcher found low-level warrants make it difficult for 
charged individuals to interact with legitimate institutions for fear of arrest and incarceration (Goffman, 2009). Furthermore, the current legal system can be used by kin and intimate partners to control the homeless individual through the tendency of some legal authorities to attribute superior legal legitimacy or standing to them instead of the charged individual.

Relatively little is known concerning factors that hinder employment among mentally ill homeless individuals (Pickett-Schenk, Cook, Grey, Bang hart, Rosenheck, \& Randolph, 2002). An extensive legal history or criminal record has been found to predict poor outcomes in searching for competitive employment among homeless veterans (LePage et al., 2005), with imprisonment and mental illness being significant hindrances to finding employment. Other researchers (Calsyn et al., 2005) noted the need for judicial reform in regard to the treatment of homeless persons before the courts.

Comparisons of social welfare and economic policies across cultures highlight the impact of structural factors as a significant contributor to the incidence of homelessness. One example of a major structural change in another culture was that of the Japanese tradition of lifetime employment with a single employer and its consequence. That major structural change in the Japanese economic structure resulted in a decline in lifetime employment and was correlated with an increase in homelessness among older males (Okamoto, 2007). A review of the rates of income distribution among various countries suggests a "causal link" between rates of homelessness and a country's income distribution (Shinn, 2007, p. 661). Income inequality has been defined as the "gap" between persons at the upper, middle, and lower levels of a population's economy (Bernstein, Mishel, \& Brocht, 2000 , p. 1). In a review of homelessness across the globe, Shinn (2007) posited that income inequality and homelessness was highest in the United States. In contrast, European countries with higher social welfare expenditures and less income inequality also had lower levels of homelessness. Similarly, countries such as Japan that now have policies comparable to the United States now have higher levels of homelessness (Okamoto, 2007).

Differences in the availability of government subsidized housing suggest a relationship between welfare policies and varying levels of homelessness across cultures. A review of the rates of subsidized housing in Europe and America reveal striking differences. For example, within the United Kingdom approximately $20-30 \%$ of housing is subsidized (Fitzpatrick \& Christian, 2006), compared to only $1.8 \%$ of all occupied units in the United States (U.S. Census Bureau, as cited in Shinn, 2007).

\section{METHOD}

\section{Participants and Procedure}

Homeless individuals are not usually easily accessible in large groups. The researchers gained permission for this exploratory research to conduct a survey of those attending two area events for homeless persons organized by the Veterans Administration (VA) and two of the area's homeless coalitions - the EscaRosa Coalition on the Homeless (ECOH) and the Okaloosa-Walton Coalition. The events known as VA Stand Downs are held annually during the fall across the United States to provide comprehensive supportive services to help homeless veterans and other homeless persons survive the winter months. Many community organizations participate in the two one day events during which they provide the following: a hot meal and food supplies; showers, shaves and haircuts; winter clothing, thermals, and boots; tents and sleeping bags; and toiletries and other winter supplies. Other important services were also offered on-site, including: medical and dental exams and services, legal services, VA assistance, VA mental health services, as well as social service and job services to the homeless in the region.

The focus of this study is the participants of the two VA Stand Down events held in two nearby northwest Florida counties, Escambia and Okaloosa, during the fall of 2009. Those sites became available to the researchers due to their knowing to the key organizers and stakeholders of the event who were supportive of the study. The researchers were allowed access with the condition that participation in the study by those attending was voluntary.

The researchers developed a questionnaire to survey homeless persons attending the two VA Stand Down events in the two counties. The principal researchers and research assistants attended each full day event and recruited participants for the survey while assisting those attending during the day. Survey participants were promised confidentiality of their individual responses, were questioned away from other attendees, and were thanked for their help and time (about 10-15 minutes). To avoid any potential 
embarrassment from reading problems, the questions were read by the interviewer. From the hundreds attending the two area events, a purposive sample of homeless individuals $(n=186)$ was surveyed, with 137 from Escambia County and 49 from Okaloosa County.

As reported by the two homeless coalitions in their annual count just two months later, the combined homeless population for 2010 in Okaloosa, Walton, Escambia and Santa Rosa counties in northwest Florida was 3,292 individuals (Department of Children and Families, 2010). In terms of social and economic characteristics, Escambia County had a population of 294,410 with $28 \%$ non-white according to the 2000 U.S. Census. Escambia County's median household income was $\$ 35,234$ with a $3.7 \%$ unemployment rate. In terms of the mobility of Escambia County residents, $52 \%$ of the householders moved into the county during the past five years. The population of Okaloosa County $(170,498)$ was about $58 \%$ of Escambia County's, with the percentage of non-white residents being much smaller at $16.6 \%$ in Okaloosa as compared to its counterpart $(28 \%)$. Okaloosa appears to have a more homogeneous population in regard to racial composition than Escambia. Okaloosa County's median household income and unemployment rate were $\$ 41,474$ and $2.7 \%$, respectively. About $55 \%$ of household residents moved into Okaloosa within the past five years. The social and economic characteristics reviewed indicate Okaloosa with its smaller population had somewhat better economic conditions as well as a slightly higher mobility rate of residents coming into the county than Escambia did.

\section{Measurements and Analysis}

The questionnaire for this study included items related to the following: social-demographic information; current homeless status information; offense history; and the respondents' perceptions of factors that may limit them from participating in a misdemeanor resolution program. In regard to demographics, the respondents were asked for their age in years at the time of survey, race, gender, and the highest education completed (high school or less, and college or more). In addition, the researchers asked about their marital status (i.e.; single, married, divorced, and other (includes widowed or living together), and if they have a minor child. The survey included questions about respondents' homeless status and incarceration history with the following questions: 1) Are you currently (without a regular place to live) homeless? (Yes=1, No=0); 2) Have you been homeless for one continuous year? ( $\mathrm{Yes}=1, \mathrm{No}=0)$; and 3) Have you ever been incarcerated? ( $\mathrm{Yes}=1, \mathrm{No}=0)$. The respondents were also asked if they are a veteran (Yes=1, No=0), and if they had an outstanding misdemeanor charge at the time of survey (Yes=1, $\mathrm{No}=0$ ). In terms of factors that may be related to and/or hindrances to misdemeanor resolution, participants were asked a set of ten statements with five Likert-type responses ( 1 = strongly disagree; 2 = disagree; 3 = neutral; 4 = agree; and $5=$ strongly agree). Researchers asked respondents to assess how important each item was to their seeking resolution of their misdemeanor offense(s). After identifying the most significant factors, the researchers applied a factor analysis procedure in order to explore common themes among the many factors that may be related to hindering the sample respondents from resolving their misdemeanor(s). Ordinary Least Squares (OLS) Regression Model estimates were developed to examine the relationship between the dimensions of barriers and other selected variables.

\section{RESULTS}

As seen in Table 1, the average age of sample respondents was about 49 with the eldest being 78 and the youngest being 21 years of age. More than half of the participants identified themselves as "Caucasian" (53.2\%), followed by African American (36\%), and "other" (11.8\%). The purposive sample consisted of four times as many males (80.1\%) as females (19.9\%), with about two-thirds of respondents (67.4\%) reporting "high school or less" and almost a third with "some college or more" as their highest education. In regard to marital status, over half of the respondents were "single" $(52.2 \%)$, followed by "divorced or separated" $(29.0 \%)$, while less than six \% were married at the time of the survey. In addition, about one fourth of the participants $(25.8 \%)$ reported they had a minor child. Veterans comprised a majority of sample respondents $(n=109,58.6 \%)$. In terms of current homeless status, $63.4 \%$ of sample respondents were now homeless, while $56.5 \%$ of them had been "homeless for one continuous year." Almost three- fourths of the participants $(74.2 \%)$ had been incarcerated in their lifetime, while only $23(12.4 \%)$ of the respondents reported an outstanding misdemeanor charge at the time of the survey. Given Okaloosa County's population is $58 \%$ of Escambia County's, more homeless persons attended and were surveyed at the Escambia County Stand Down $[n=137$ (73\% of the sample)]. 
Table 1: Descriptive Statistics of Variables

\begin{tabular}{|c|c|c|c|c|c|}
\hline Variables & Frequency & Percent (\%) & & & $\mathbf{N}$ \\
\hline Race & & & & & 186 \\
\hline Caucasian & 99 & 53.2 & & & \\
\hline Other & 18 & 11.8 & & & \\
\hline Male & 149 & 80.1 & & & \\
\hline Female & 37 & 19.9 & & & \\
\hline Education & & & & & 174 \\
\hline High school or less & 126 & 67.4 & & & \\
\hline Married & 11 & 5.9 & & & \\
\hline Divorced/separated & 54 & 29.0 & & & \\
\hline Others & 24 & 12.9 & & & \\
\hline Having a minor child & & & & & 186 \\
\hline Yes & 48 & 25.8 & & & \\
\hline No & 138 & 74.2 & & & \\
\hline Veteran & & & & & 186 \\
\hline Yes & 109 & 58.6 & & & \\
\hline Yes & 105 & 56.5 & & & \\
\hline No & 81 & 43.5 & & & \\
\hline Prior Incarceration & & & & & 186 \\
\hline Yes & 138 & 74.2 & & & \\
\hline No & 48 & 25.8 & & & \\
\hline Current misdemeanor & & & & & 186 \\
\hline Yes & 23 & 12.4 & & & \\
\hline \multirow[t]{2}{*}{ No } & 163 & 87.6 & & & \\
\hline & Min. & Max. & M & S.D. & \\
\hline Age & 21 & 78 & 48.97 & 9.14 & 177 \\
\hline
\end{tabular}

Table 2 displays the mean scores for each barrier as well as their factor loading scores for the identified dimensions. According to the factor analysis, three dimensions were shared among the barriers: personal, physical, and motivational. Reliability analysis confirmed the results of the factor analysis with Cronbach's $\alpha$ or alpha scores for the three dimensions being greater than the selected threshold value of 0.7 . A comparison of the mean scores indicated the survey participants ranked the motivational dimension higher 
Table 2: Descriptive and Factor Analysis Results for Barriers

\begin{tabular}{|c|c|c|c|c|}
\hline Factors & Mean & S.D. & Factor loading & Chronbach's a \\
\hline Personal barriers & & & & 0.772 \\
\hline $\begin{array}{c}\text { I have a tough time keeping track of the misdemeanor court } \\
\text { process (dates). }\end{array}$ & 3.47 & 1.75 & 0.855 & \\
\hline Personal problems interfere with me going to misdemeanor court. & 3.73 & 1.62 & 0.766 & \\
\hline $\begin{array}{l}\text { I don't resolve misdemeanor charges because I am fearful of the } \\
\text { sentence. }\end{array}$ & 3.68 & 1.68 & 0.616 & \\
\hline Physical barriers & & & & 0.759 \\
\hline $\begin{array}{c}\text { Court location is a hindrance to me in resolving misdemeanor } \\
\text { charges. }\end{array}$ & 3.31 & 1.77 & 0.774 & \\
\hline It is inconvenient for me to resolve outstanding misdemeanors. & 3.06 & 1.85 & 0.649 & \\
\hline $\begin{array}{c}\text { Lack of transportation is the primary reason I do not resolve } \\
\text { outstanding misdemeanors. }\end{array}$ & 3.03 & 1.84 & 0.773 & \\
\hline Weather is a barrier to me attending misdemeanor court. & 3.42 & 1.74 & 0.729 & \\
\hline Motivational barriers & & & & 0.701 \\
\hline $\begin{array}{c}\text { I don't care about resolving any outstanding misdemeanor } \\
\text { charges I have. }\end{array}$ & 4.14 & 1.53 & 0.871 & \\
\hline $\begin{array}{l}\text { I don't attend misdemeanor court due to the time being } \\
\text { inconvenient. }\end{array}$ & 3.99 & 1.47 & 0.627 & \\
\hline I don't attend misdemeanor court due to a lack of information. & 3.88 & 1.52 & 0.647 & \\
\hline
\end{tabular}

than the other dimensions. In other words, on average respondents did not resolve their misdemeanor charges mostly due to very low motivation to do so. The second highest dimension was Personal Barriers followed by Physical Barriers. The order suggests the respondents were less likely to be hindered by Physical Barriers compared to Motivational and Personal ones when considering whether to seek misdemeanor resolution. Among barrier items, "I don't care about resolving any outstanding misdemeanor charges...." was the highest ranked item $(M=4.14)$. In addition, the respondents responded that an "inconvenient time" $(\mathrm{M}=3.99)$ and "lack of information" $(\mathrm{M}=3.88)$ were possible reasons they would not resolve misdemeanor charges.

Three multiple regression models were developed to estimate the relationship between the identified dimensions of barriers (Personal, Physical, and Motivational) and other selected variables. (see Table 3) Among the three models, only the Personal Dimension model had a significant model fit $(F=2.91$, $p<.01)$. Two variables in the model, the participants' age and being a veteran, yielded a significant relationship with the Personal Dimension of barriers, and both relationships were in the positive direction. In other words, older respondents and veterans considered their personal barriers to be more important than their counterparts did in deciding to participate in misdemeanor resolution. In addition, veterans also rated the Physical Dimension of barriers to be significantly more substantial than non-veterans, while none of other variables had a significant relationship. There was no significant relationship between the selected variables and the Motivational Dimension of barriers.

\section{DISCUSSION}

The research suggests homeless individuals face multiple barriers when considering to resolve misdemeanor charges. This study reported on three major themes or barriers: personal, physical, and motivational factors. Those barriers can have a negative influence on a person's ability to gain employment and change his/her status from homeless to "housed." The barriers may prevent the occurrence of a potential series of actions by individuals trying to improve their current status: may hinder a person from seeking resolution of misdemeanor charges, which in turn may thwart job seeking and attainment, and therefore may lead to remaining homeless.

The implications of these barriers for social workers and court personnel include: the use of case management by professional social workers, the 
Table 3: OLS Regression of Dimensions of Barriers on Variables (unstandardized)

\begin{tabular}{|c|c|c|c|}
\hline \multirow[t]{2}{*}{ Independent variables } & \multicolumn{3}{|c|}{ Dimensions of barriers $^{a}$} \\
\hline & Personal & Physical & Motivational \\
\hline Age (in years) & $0.08(0.04)$ * & $-0.03(0.06)$ & $-0.02(0.04)$ \\
\hline African American & $0.46(0.71)$ & $1.25(0.97)$ & $-0.34(0.64)$ \\
\hline Male & $1.77(0.98)$ & $1.05(1.34)$ & $0.41(0.89)$ \\
\hline Education $(1=\text { some college or more })^{b}$ & $-0.17(0.82)$ & $0.11(1.12)$ & $1.19(0.74)$ \\
\hline Have a minor child ( 1 = yes) & $1.19(0.67)$ & $0.15(0.92)$ & $0.76(0.61)$ \\
\hline Being a veteran ( $1=$ yes $)$ & $2.06(0.78)^{* *}$ & $2.59(1.06)$ * & $0.81(0.71)$ \\
\hline Prior incarceration(s) (1 = yes) & $0.99(0.86)$ & $-1.18(1.17)$ & $0.71(0.78)$ \\
\hline Currently homeless ( 1 = yes) & $0.26(0.76)$ & $-0.29(1.04)$ & $0.41(0.69)$ \\
\hline $\begin{array}{l}\text { Have an outstanding misdemeanor charge } \\
\qquad(1=\text { yes })\end{array}$ & $-1.99(1.05)$ & $-0.75(1.44)$ & $-1.54(0.95)$ \\
\hline Constant & $3.26(2.74)$ & $12.71(3.75)^{* *}$ & $11.48(2.48)^{* * *}$ \\
\hline $\mathrm{R}^{2}$ & 0.41 & 0.27 & 0.28 \\
\hline adjusted $\mathrm{R}^{2}$ & 0.17 & 0.07 & 0.08 \\
\hline $\mathrm{F}$ & 2.91 ** & 1.21 & 1.23 \\
\hline
\end{tabular}

${ }^{*} p<.05 ;{ }^{* *} p<.01 ;{ }^{* * *} p<.001,(\mathrm{~N}=186)$

a Standard errors in parentheses.

${ }^{\mathrm{b}}$ Reference group: high school or less.

development of creative courtroom environments which may include reaching out to homeless persons in nontraditional settings, and improving collaboration among court service personnel, homeless program advocates, and social service workers. Social workers assisting a homeless client who has personal barriers hindering a misdemeanor resolution should consider a case management approach to their work. Some homeless individuals may not have the wherewithal or means to overcome their personal barriers to seeking resolution of a misdemeanor charge. Case management has been found to be effective in a variety of environments with homeless individuals, including: reducing the number of emergency room visits by homeless patients (Sadowski, Kee, \& VanderWeele, 2009), improving housing and mental health outcomes of homeless veterans (Kasprow \& Rosenheck, 2007), and for increasing the number of homeless women finding shelter (Heslin, Andersen, \& Gelberg, 2003). The case management approach may be especially helpful to older homeless veterans who appear to be at greater risk for having a personal barrier to resolving a misdemeanor charge.

In regard to the second or physical barrier, there are direct implications from this study for agencies that assist homeless individuals who face physical barriers to their participation in a misdemeanor resolution program. What alternatives are available to assist?
One unique alternative program has been developed and implemented by Judge Pat Maney of the Okaloosa County Court. The program addresses the physical barriers that some homeless persons face in resolving their misdemeanor charges. Instead of waiting for a homeless person with a charge to come to his court or turn himself in to the court, Judge Maney reaches out and brings an informal version of his courtroom to the facility where the VA Stand Down is held in Okaloosa County, Florida. The homeless persons attending have the option of resolving any outstanding misdemeanor warrants during the Stand Down. Judge Maney is sensitive to the fact that some homeless individuals do not wish to come under the jurisdiction of his court or any court. Consequently, he sets up the "court" in a room at the end of the hall of the facility where the homeless are being served during the VA Stand Down. Homeless individuals are informed of the courts presence and can choose to participate. A number of homeless individuals have found Judge Maney's unique approach to be very helpful in resolving outstanding misdemeanors (Herzog, 2011). However, it is unknown if the homeless view the benefits of resolving misdemeanors as greater than the risk of coming under the jurisdiction of the courts.

The third factor identified was motivational barriers. Social workers should work closely with court personnel to try to increase the motivation of homeless 
individuals to resolve their misdemeanor charges. Indeed, Solomon and Draine (1999) suggest instituting collaborative efforts between mental health providers and court personnel in working with individuals who are homeless. Increased levels of supervision may enhance a homeless individual's degree of motivation to resolve misdemeanor charges. Given the many respondents who answered the item "I don't care about resolving any outstanding misdemeanor charges....", the question arises as to why. One reason may be the prior experiences of others and themselves with the courts where they were immediately incarcerated as a result of their appearance. The fear of the loss of freedom and their immediate imprisonment from their court appearance is a real one and needs to be addressed in follow up research efforts. Can a misdemeanor resolution program really remove the risk of jail time for the person who is homeless that appears? A "yes" answer to the risk and fear of incarceration question may increase the motivation of individuals to participate.

The results should be interpreted cautiously as this research was conducted with a purposive sample. Due to the nature of the event, a random sample was not possible. The individuals in the sample were recruited and voluntarily participated in the study, therefore the sample may not be representative and the findings not generalizable to the larger population of homeless persons with outstanding misdemeanor charges. Often research with homeless populations is conducted in large urban settings. This study differed as it was conducted more than 200 miles from a large urban area or city center. Urban homeless populations may differ from suburban and rural populations in significant ways.

Further research is needed which could draw from a random sample of homeless persons in order to increase generalizability. Continued research is needed to advance the identification of the barriers for resolution that homeless persons with outstanding misdemeanor charges face. The survey items should be furthered developed using improved measures of the factors previously identified. Especially important is the question as to why there is a lack of motivation for resolution. This exploratory research makes a small contribution to the paucity of literature on homelessness and their barriers to the resolution of misdemeanor charges on their court record which may result in incarceration. This overlooked subject can have a considerable impact on homeless individuals facing misdemeanor warrants to reduce future incarcerations and increase their employability.

\section{REFERENCES}

Bernstein, J., Mishel, L., \& Brocht, C. (2000). Any way you cut it: Income inequality on the rise regardless of how it's measured. Economic Policy Institute Briefing Paper. Retrieved from www.epi.org/publication/briefingpapers_inequality_inequality/

U.S. Census (2012). United States Census 2000. Washington, DC: United States Department of Commerce. Economics and Statistics Administration.

Calsyn, R., Yonker, R., Lemming, M., Morse, G., \& Klinkenberg, W. (2005). Impact of assertive community treatment and client characteristics on criminal justice outcomes in dual disorder homeless individuals. Criminal Behavior and Mental Health, $15,236-248$.

http://dx.doi.org/10.1002/cbm.24

Cohen, C. (1999). Aging and homelessness. The Gerontologist, 39, 5-15.

http://dx.doi.org/10.1093/geront/39.1.5

Crane, M., Byrne, K., Fu, R., Lipmann, B., Mirabelli, F., RotaBartelink, A.,...Warnes, A.M. (2005). The causes of homelessness in later life: Findings from a 3-nation study. Journal of Gerontology, 60B(3), S152-S159. http://dx.doi.org/10.1093/geronb/60.3.S152

Department of Children and Families (2010). Homeless Conditions in Florida. State of Florida: Council on Homelessness Annual Report. Retrieved from www.dcf.state.fl.us/programs/homelessness.docs/2010Coun cilReport.pdf

Elliot, M., \& Krivo, L. (1991). Structural determinants of homelessness in the United States. Social Problems, 38(1), 113-131.

http://dx.doi.org/10.2307/800641

European Federation of National Organizations working with the Homeless (FEANTSA). (2010). How to measure and monitor homelessness at EU level. Retrieved from http://www.feantsa.org/files/freshstart/Working_Groups/Data_ collection/2010/statements/homelessnessmeasurement mar ch_2010en.pdf

Fitzpatrick, S., \& Christian, J. (2006). Comparing homelessness research in the U.S. and Britain. European Journal of Housing Policy, 6(3), 313-333. http://dx.doi.org/10.1080/14616710600973151

Goffman, A. (2009). On the run: Wanted men in a Philadelphia ghetto. American Sociological Review, 74(3), 339-357. http://dx.doi.org/10.1177/000312240907400301

Greenberg, G., \& Rosenheck, R. (2008). Jail Incarceration, Homelessness, and Mental Health: A National Study. Psychiatric Services, 59(2), 170-177.

http://dx.doi.org/10.1176/appi.ps.59.2.170

Herzog, J. (2011). Misdemeanor Resolution Stand-down Survey Results. Technical report for Judge Maney of the Okaloosa County Court, $\mathrm{FI}$.

Heslin, K., Andersen, R., \& Gelberg, L. (2003). Case Management and Access to Services for Homeless Women. Journal of Health Care for the Poor and Underserved, 14(1), 34-51.

Kasprow, W., \& Rosenheck, R. (2007). Outcomes of Critical Time Intervention Case Management of Homeless Veterans after Psychiatric Services. Psychiatric Services, 58(7), 929-935. http://dx.doi.org/10.1176/appi.ps.58.7.929

LePage, J., Bluitt, M., House-Hatfield, T., McAdams, H., Burdick, M., Dudley, D., Michaels, M., Merrell, C., Otto, S., Lenger-Gvist, J., Eisworth, J., Newton, J., \& Gaston, C. (2005). Improving Success in a Veterans Homeless Domiciliary Vocational 
Program: Model Development and Evaluation. Rehabilitation Psychology, 50(3), 297-304.

http://dx.doi.org/10.1037/0090-5550.50.3.297

Minnery, J., \& Greenhalgh, E. (2007). Approaches to homelessness policy in Europe, the United States, and Australia. Journal of Social Issues, 63(3), 641-655. http://dx.doi.org/10.1111/j.1540-4560.2007.00528.x

Miraftab, F. (2004). Neoliberalism and casualization of public sector services: The case of waste collection services in Cape Town, South Africa. International Journal of Urban and Regional Resources, 28(4), 874-892. http://dx.doi.org/10.1111/j.0309-1317.2004.00557.x

Misdemeanor Guide (2012). Florida Misdemeanors. Retrieved from www.misdemeanorguide.com

National Coalition for the Homeless (2012). Who is homeless? Factsheets, pp. 1-5. Retrieved from www.nationalhomeless.org/factsheets/who.html

Okamoto, Y. (2007). A comparative study of homelessness in the United Kingdom and Japan. Journal of Social Issues, 63(3), 525-542. http://dx.doi.org/10.1111/j.1540-4560.2007.00522.x

Pickett-Schenk, S., Cook, J., Grey, D., Bang hart, M., Rosenheck, R., \& Randolph, F. (2002). Employment Histories of Homeless Persons with Mental Illness. Community Mental Health Journal, 38(3), 199-211. http://dx.doi.org/10.1023/A:1015211622877

Sadowski, L., Kee, R., \& VanderWeele, T. (2009), Effect of a Housing and Case Management Program on Emergency
Department Visits and Hospitalizations Among Chronically III Homeless Adults, Journal of the American Medical Association, 301(17), 1771-1778. http://dx.doi.org/10.1001/jama.2009.561

Seidner, A., Burling, T., Fisher, L., \& Blair, T. (1990). Characteristics of Telephone Applicants to a Residential Rehabilitation Program for Homeless Veterans. Journal of Consulting and Clinical Psychology, 58(6), 825-831. http://dx.doi.org/10.1037/0022-006X.58.6.825

Shinn, M. (2007). International homelessness: Policy, socio-cultural and individual perspectives. Journal of Social Issues, 63(3), 657-677. http://dx.doi.org/10.1111/j.1540-4560.2007.00529.x

Tolomiczenko, G., \& Goering, P. (2001). Gender differences in legal involvement among homeless shelter users. International Journal of Law and Psychiatry, 24, 583-593. http://dx.doi.org/10.1016/S0160-2527(00)00068-6

Travis, J. (2002). Invisible punishment: An instrument of social exclusion. In M. Mauer \& M. Chesney- Lind (Eds.), Invisible punishment: The collateral consequences of mass imprisonment (15-36). New Press: New York, NY.

White, M., Chafetz, L., Collins-Bride, G., \& Nickens, J. (2006). History Of Arrest, Incarceration and Victimization In CommunityBased Severely Mentally III. Journal of Community Health. 31(2), 123-135 http://dx.doi.org/10.1007/s10900-005-9005-1

\section{DOI: http://dx.doi.org/10.6000/1929-4409.2012.01.18}

(C) 2012 Herzog et al.; Licensee Lifescience Global.

This is an open access article licensed under the terms of the Creative Commons Attribution Non-Commercial License (http://creativecommons.org/licenses/by-nc/3.0/) which permits unrestricted, non-commercial use, distribution and reproduction in any medium, provided the work is properly cited. 